the screening programme, and the savings. Turning to the "good news" in his presentation, he illustrated how mathematical modelling could be used to analyse limited data in order to make better decisions. He asked the audience to imagine that they had $\$ 400 \mathrm{~m}$ to spend on screening for a population of a million adults and to choose between cholesterol screening as recommended by the national cholesterol education programme and breast screening as recommended by the American Cancer Society. These are two of the best studied screening methods, and much of the information needed for making policy decisions is available.

Cholesterol screening according to the recommended protocol could prevent 9620 events (including 340 sudden deaths, 2760 myocardial infarctions, and other conditions, some of them only poorly defined because of imprecise data) at a cost of $\$ 449 \mathrm{~m}$ with a saving of $\$ 101 \mathrm{~m}$ (net cost $\$ 348 \mathrm{~m}$ ); breast screening would save 222 lives at a cost of $\$ 296 \mathrm{~m}$ but with a saving of only $\$ 5 \mathrm{~m}$ (net cost $\$ 291 \mathrm{~m}$ ). A purchaser might thus opt for cholesterol screening, but Professor Eddy set his computer to adopt a more selective method of deciding who should be treated for hypercholesterolaemia - very much in the manner described in last week's $B M \mathcal{F}$ by Professor Hugh Tunstall-Pedoe (28 September, p 744). The result is that you can prevent the same number of events with consequently the same saving (which is what Professor Eddy told his computer to do) at a cost of $\$ 192 \mathrm{~m}$, giving a net cost of $\$ 91 \mathrm{~m}$. The purchaser with $\$ 400 \mathrm{~m}$ could then have both cholesterol and breast screening with $\$ 18 \mathrm{~m}$ change. The computer could go further and be set to achieve higher benefits at lower costs.

This is how important information can be, but one of the problems is that the information comes out of a mathematical model-and doctors feel uncomfortable with such models. The doctors who devised the national cholesterol education programme responded to his computer manipulation by saying that the protocol he had devised was too complicated to use. Professor Eddy is sympathetic but points out that medicine is far too complex an activity to be conducted by human minds unaided by computers: "We've been trying that for two millennia and look where we've got to." Planes are landed better by computers than humans-especially in rough weather-and much of medicine is more complicated than landing a plane. Professor Eddy thus has a fantasy of a health room equivalent to the control room at an airport, and the health room would contain all the information needed to make decisions to improve health. Like all fantasies this must be treated with caution, and purchasers in the NHS and elsewhere are faced now with making difficult choices with grossly inadequate information.

The afternoon session of the conference tackled some of the hard questions faced by purchasers. Firstly, should they specify care processes or health gain in contracts? Whatever you go for, make your decision in an alliance with providers, said one group asked to answer the question. Professor Eddy thought that for now purchasers would have to specify processes rather than outcomes because outcomes were delayed and probabilistic. Secondly, where should purchasers get their advice on clinical advances? They had to go to local providers, everybody agreed, but "get them to provide their evidence," said Professor Eddy. Go as well, the meeting agreed, to national and international bodies, set priorities, and look for sophisticated analyses that use the best data. And try to avoid duplication, said Professor Eddy: "In the United States we have 200 groups working on the same 15 problems." Finally, how can doctors be encouraged to use this information? There were mutterings about participation, ownership, alliances, quality assurance, education, and cultural change, but Professor Eddy concluded: "Get doctors to understand how much they need reliable information. What could be worse than two millennia spent making life and death decisions with inadequate information?"

Editor, $B M \mathcal{F}$

RICHARD SMITH

\begin{abstract}
1 de Solla Price D. The development and structure of the biomedical literature. In: Warren KS, ed. Coping with the biomedical literature. New York: Praegex, 1981:3-16.

2 Lock S. Introduction. In: Lock S, ed. The future of medical journals. London: BM7, 1991:1-8.

3 Williamson JW, Goldschmidt PG, Colton T. The quality of medical literature: an analysis of

Williamson JW, Goldschmidt PG, Colton T. The quality of medical literature: an analysis of
validation assessments. In: Bailar JC, Mosteller F. Medical use of statistics. Waltham, Massachusetts: NEJM Books, 1986.
\end{abstract}

\title{
Exogenous surfactants
}

\section{They work and are expensive}

In 1959 Avery and Mead postulated that deficiency of surface active material in the lungs of preterm infants caused hyaline membrane disease. ${ }^{1}$ Although early attempts to treat respiratory distress in newborn infants with exogenous surfactant were unsuccessful, Fujiwara and colleagues reported in 1980 that 10 preterm neonates benefited from a mixture of phospholipids and bovine lung extract instilled into their endotracheal tubes. ${ }^{2}$ During the next decade there was much scientific and commercial interest in developing an effective surfactant which could be safely administered to preterm infants. Respiratory problems and their sequelae remain an important source of mortality and morbidity in very low birthweight infants despite the advances that have occurred in ventilatory management and supportive care.

Exogenous surfactants have been derived from several sources. Effective "natural" surfactants have been extracted from the lungs of pigs, cows, and calves and from human amniotic fluid. These may be modified by adding synthetic phospholipids. Other surfactants are completely artificial, do not contain animal or human protein, and are synthesised from the main phospholipid components of natural surfactants. Artificial lung expanding compound ("ALEC") contains dipalmitoylphosphatidylcholine and phosphatidylglycerol and has been extensively evaluated. ${ }^{3}$ Colfosceril palmitate ("Exosurf") is a synthetic mixture of dipalmitoylphosphatidylcholine, tyloxapol, and an alcohol, hexadecanol, which acts like the protein in natural surfactants to aid distribution of the surface active material over the interface between fluid and air in the lung. Colfosceril palmitate now has a product licence in the United Kingdom for the treatment of established respiratory distress syndrome in infants with a birth weight of over $700 \mathrm{~g}$. Other surfactants, including natural products, are likely to become available commercially soon.

The clinical evaluation of treatment with exogenous surfactant has been thorough and prolonged, and 34 randomised controlled trials in over 6000 infants are included in the Oxford Database of Perinatal Trials. ${ }^{+}$Overviews of the 
clinical trials by Soll ${ }^{4}$ and Morley ${ }^{5}$ show beneficial effects of both natural and synthetic surfactants. Mortality is reduced by about $40 \%$ when exogenous surfactant is used to treat respiratory distress syndrome, and a similar reduction in mortality is achieved by using a prophylactic regimen in all high risk preterm infants. ${ }^{+}$Pneumothoraces are less common, but there is no clear effect on the incidence of bronchopulmonary dysplasia, intraventricular haemorrhage, or patent ductus arteriosus. ${ }^{5}$ Early follow up studies suggest that there is no increase in the number of handicapped survivors. ${ }^{6}$

Colfosceril palmitate increases the incidence of pulmonary haemorrhage, ${ }^{7}$ especially in the smallest infants (birth weight $<700 \mathrm{~g}$ ) which has been attributed to an increase in pulmonary blood flow as lung compliance increases and pulmonary vascular resistance falls. Blockage of the endotracheal tube may occur after surfactant is given, and intensive monitoring and skilled supportive care are required during and after the procedure. Introducing a considerable volume of fluid ( $5 \mathrm{ml}$ colfosceril palmitate $/ \mathrm{kg}$ body weight) into the endotracheal tube of a sick ventilated infant and the subsequent manipulation of ventilator settings are not trivial procedures. Reproducing the results achieved in clinical trials cannot be guaranteed if surfactant is given with inadequate monitoring in units without intensive care facilities and skilled staff. The American Academy of Pediatrics has warned against the "potential misue of this form of therapy." 8

Surfactant is expensive. Two doses of colfosceril palmitate for a $1500 \mathrm{~g}$ infant costs $£ 628$; for an $1800 \mathrm{~g}$ infant the cost is $£ 1256$. Determining whether prophylaxis is more effective than treatment and designing the most effective and economic dose regimen are therefore essential. Attempting to provide the answers is a large collaborative trial, OSIRIS, coordinated by the National Perinatal Epidemiology Unit in the United Kingdom, which has recruited over 5000 infants from 21 countries. As natural surfactants become commercially available, comparisons of various surfactants in randomised, "head to head" trials will be necessary. Many questions remain unanswered. Which is the best surfactant? Which infants should receive it? When, how much, how often?

The advent of treatment with surfactant has made it even clearer that there is more to neonatal lung disease than deficiency of surfactant. The first week of a ventilated infant's life may be much more stable after treatment with surfactant, but the lung is still highly susceptible to the effects of barotrauma, oedema, retained secretions, infections, and other possible causes of chronic neonatal lung disease.

The main cost of treatment with surfactant is not the price of the drug but the cost of the intensive care that the additional survivors require. Tubman et al calculated that each additional surviving infant treated with surfactant costs $£ 13720$. $^{9}$ In that study, however, surfactant was given to small and sick infants, in whom the reduction in mortality is most evident and the cost of increased survival highest. The financial benefits of surfactant are likely to be more apparent in the treatment of larger babies, who are unlikely to die of their disease with conventional treatment, but whose requirement for intensive care may be reduced by surfactant..$^{10}$

A treatment that certainly saves lives when given to very small babies will be welcomed by parents and neonatologists. That it probably saves money when given to larger babies should help in our negotiations over the drug bill.

Consultant Neonatologist

PETER HOPE

John Radcliffe Hospital,

Oxford OX3 9DU

1 Avery ME, Mead J. Surface properties in relation to atalectasis and hyaline membrane disease. Am $\mathcal{F}$ Dis Child 1959;97:517-23.

2 Fujiwara T, Maeta H, Chida S, Morita T, Watabe Y, Abe T. Artificial surfactant therapy in hyaline-membrane disease. Lancet 1980;i:55-9.

3 Ten Centre Study Group. Ten centre trial of artificial surfactant (ALEC) in very premature babies. BMF 1987;294:991-6.

4 Soll RF. Overviews on exogenous surfactant therapy. In: Chalmers I, ed. Oxford Database of Perinatal Trials. Version 1.2, Disc issue 5, February 1991, Records 5206, 5207, 5252, 5253. Perinatal Trals. Version 1.2, Disc issue 5, February 1991
Oxford Electronic Publishing, Oxford University Press.

5 Morley CJ. Surfactant treatment for premature babies - a review of clinical trials. Arch Dis Child 1991;66:445-50.

6 Morley CJ, Morley R. Follow up of premature babies treated with artificial surfactant (ALEC). Arch Dis Child 1990;65:667-9.

7 Long W, Stevenson D, Pauley T, Leblanc M, and the American Exosurf Neonatal Study Group 1. Effects of a single prophylactic dose of Exosurf Neonatal in $215500-700 \mathrm{~g}$ infants. Pediatr Res 1991;29:A1320.

8 Committee on Fetus and Newborn, American Academy of Pediatrics. Surfactant replacement for respiratory distress syndrome. Pediatrics 1991;87:946-7.

9 Tubman TRJ, Halliday HL, Normand C. Cost of surfactant replacement treatment for severe neonatal respiratory distress syndrome: a randomised controlled trial. $B M 7$ 1990;301:84-5.

10 Schumacher R, Burchfield D, Vaughan R, Courtney S, McKenzie K, Alexander S, et al. Economic impact two rescue doses of Exosurf Neonatal in $>1350 \mathrm{~g}$ infants. Pediatr Res 1991;29:A1570.

\title{
Verocytotoxin producing Escherichia coli
}

\author{
Newish bug on the block
}

What a difference the right diagnostic technology makes. Virtually unknown before $1977,{ }^{1}$ campylobacter species emerged as a leading cause of bacterial food poisoning in the United Kingdom within four years. ${ }^{2}$ The previously little known verocytotoxin producing Escherichia coli may be heading for similar notoriety. A recent example of its pathogenicity was the outbreak of infection associated with eating burgers bought from a fast food restaurant. This resulted in 24 people developing haemorrhagic colitis, three of whom developed the haemolytic-uraemic syndrome. ${ }^{3}$

Although verocytotoxin producing $E$ coli was originally identified in $1971,{ }^{4}$ a further 11 years elapsed before its pathogenic importance was recognised. In 1982 Riley et al linked verocytotoxin producing $E$ coli serotype $\mathrm{O} 157: \mathrm{H} 7$ to haemorrhagic colitis - a syndrome of abdominal pain and watery diarrhoea that becomes bloody - after investigating an outbreak of gastroenteritis related to eating beef products.
The following year Karmali et al showed that $\mathrm{O} 157$ and other verocytotoxin producing serotypes were important causes of sporadic haemolytic-uraemic syndrome. ${ }^{6}$ Occurring particularly in children under 5 , this syndrome consists of acute renal failure, thrombocytopenia, and microangiopathic haemolytic anaemia and is preceded by diarrhoea or haemorrhagic colitis in most cases..$^{6.9}$

The spectrum of disease caused by verocytotoxin producing $E$ coli is wide and includes asymptomatic infection, ${ }^{10}$ mild non-bloody diarrhoea, ${ }^{9-13}$ thrombotic thrombocytopenic purpura (the haemolytic-uraemic syndrome with neurological signs), ${ }^{7114}$ and an illness similar to ulcerative colitis. ${ }^{1516}$ Furthermore, verocytotoxin producing $E$ coli, particularly serotype $0157: \mathrm{H} 7$, is now known to be responsible for major sporadic and epidemic disease in many countries including the United Kingdom, the United States, and Canada. ${ }^{35} 79-1214$ 17-22 